\title{
Some Notes on Forecasting of Winds Aloft by Statistical Methods ${ }^{1}$
}

\author{
JACK W. REED \\ Sandia Corporation, Albuquerque, N. Mex.
}

(Manuscript received 8 August 1966, in revised form 21 November 1966)

\section{ABSTRACT}

\begin{abstract}
Winds aloft statistics from Eniwetok were used to derive a linear regression forecast technique that verified satisfactorily in later application. Other studies showed that these principles were applicable throughout the tropical Pacific Ocean area. Time-lag correlation coefficients were found to decay exponentially with increased time except in the first $6 \mathrm{hr}$, when decay was more rapid. This has been interpreted as the effect of measurement error and small-scale turbulence.

A method was derived for removal of these random errors and, on application, time-lag correlation coefficients for each altitude were then found to decay at constant exponential rates, to at least $48 \mathrm{hr}$. This indicates that no improvement in regression forecasting can be achieved by use of multiple-term regressions from sequential data. Also, regression forecast verifications can be significantly improved by 1) removing the instrument error by hardware techniques and 2) smoothing out small-scale turbulence by multiple observation.

This general technique is also shown to be useful in forecasting for other latitudes but comparison with other forecast methods for middle and high latitudes has not been made.
\end{abstract}

\section{Introduction}

Some rather remarkable success has been demonstrated in applying simple statistics for wind predictions. To appreciate this, let us review the development of statistical forecasting. The first thing which might be done to obtain a wind forecast, completely neglecting meteorology as a predictive science, would be to make a simple observation and assume that the observed condition would persist. The standard error in this procedure would equal the standard deviation of wind changes in the forecast interval, a measure of time-dependent variability.

Having recognized the variability of wind with time, a next step to improve forecasting might be to collect a large number of observations, average them, and always predict that the climatic average wind would occur at verification time. The standard error from using this technique would be equal to the sample standard deviation, a measure of scatter in data points. If each wind were independent of each other wind in the sample, the error in using a climatic average would be only seventenths or $2^{-\frac{1}{3}}$ as large as that assuming persistence. Principles of fluid mechanics show clearly that sequential observations should not be completely independent or disconnected. Observations likewise cannot be completely connected or all wind would have ceased long ago. Developing a compromise between the two, via physical explanations and models, has been the goal of synoptic and hydrodynamic meteorology. Statistical

\footnotetext{
${ }^{1}$ This work was supported by the United States Atomic Energy
} Commission. description of a compromise model has been the subject of much later development.

Kochanski (1957) recognized that at stratospheric altitudes data collection was somewhat inadequate for synoptic forecasting and proceeded to investigate effects of various weightings to improve the combination of persistence and climatology and thus reduce forecast errors. Buell (1958) showed that these statistics could be given geometric interpretation and, from this, that error is minimized when the coefficient multiplier for the persistence term is equal to the coefficient of correlation between two observations separated by the forecast interval time.

A field experiment in the tropical Pacific by Reed ${ }^{2}$ demonstrated that, in competition with conventional meteorological service forecasts, this simple, fast, economical technique gave significantly better wind forecasts at some altitudes. A further study by Lavoie and Wiederanders ${ }^{3}$ confirmed this conclusion. They further simplified inputs and found that half-and-half, persistence and climatological average, gave adequately accurate predictions. This resulted from coincidence in that at some altitude levels and time intervals, variability was such that the correlation coefficient was nearly one-half. This conclusion would not be warranted

\footnotetext{
2 Reed, J. W., 1958: BREEZE wind forecast program. Sandia Corporation, Albuquerque, N. Mex., unpublished paper presented at Critique of Operation Hardtack Computer Weather Analyses, Los Alamos, N. Mex., 2 pp.

${ }^{3}$ Lavoie, R. I., and C. J. Wiederanders, 1960: Objective wind forecasting over the tropical pacific. University of Hawaii Institute of Geophysics Scientific Report No. 1 (also AFCRL-TN-60-832), $38 \mathrm{pp}$.
} 
for other altitudes and time intervals. Eventually a statistical program was evolved for forecast calculation over the entire tropical Pacific Ocean area by Bedient and Vederman (1964). As used today by the joint meteorological services in Hawaii certain subjective adjustments are made to purely statistical forecasts. These have proven quite beneficial, but the deviation times correlation coefficient term provides the basic computed forecast wind pattern.

It is now appropriate to review some of the earlier results in hopes of generating further improvement. It would seem obvious from synoptic reasoning that an input series of observations should give better results than a single wind input. Also, by the same argument, an input from several stations should give an improvement, as well it did, shown by Vogel, ${ }^{4}$ but at considerable increase in calculation complexity. Also, he indicated a limit to forecast ability from a large data input which was considerably approached by only single station, single observation input. It is, incidentally, difficult to compare Vogel's statistics with others for he has used as the altitude level "average" wind the average of that level and levels $5000 \mathrm{ft}$ above and below it. This approximate "mean layer wind" smooths many of the small scale turbulent effects found in ordinary data where an observer has averaged balloon paths over 1000 - or $2000-\mathrm{ft}$ layers in standardized data reduction.

One particularly bothersome point found in field trials $\left(\right.$ Reed $\left.^{5}\right)$ was that at high altitudes Joint Task Force Seven Weather Central forecasts, made almost entirely by averages from climatology, turned out to be better than statistical regression forecasts. A proposed explanation of this dilemma was that observation error was so large that it contaminated regression prediction even to the point of exceeding actual deviations of the wind from the mean.

Another analysis, of correlation coefficient decay with time, also led to the same conclusion that measurement error plus short time variation was relatively large and significant. A derived correction for these measurement error statistics in 6-hr observation sequences was made by extrapolating back to zero time interval the observed exponential decay with time of zonal wind correlation coefficients for intervals of 6-48 hr. That the logarithm. of the correlation coefficient is proportional to the time interval between observations was also found earlier by Durst (1954), Spreen, ${ }^{6}$ and Elsaesser. ${ }^{7}$ A major consequence of this condition is that a regression forecast based on a single observation cannot be improved by adding a sequence of previous observations. This was

\footnotetext{
${ }^{4}$ Vogel, R. E., 1960, A statistical technique for predicting a two dimensional vector with application. Los Alamos Scientific Laboratory Report $\mathrm{LA}-2380,84 \mathrm{pp}$.

${ }^{5}$ Reed, J. W., op. cit.

${ }^{6}$ Spreen, W. C., 1956: The distribution of temporal wind variation. Unpublished paper presented at 148th Meeting, American Meteorological Society, Asheville, N. C.

${ }_{7}$ Elsaesser, H. W., 1960: Wind variability. Air Weather Service Technical Report, AWS-TR-105-2, USAF, Washington, D. C.
}

also discussed by Buell, ${ }^{8}$ who prefers, however, based on several other considerations, to use a correlation coefficient that decays exponentially with time squared. Eniwetok data clearly do not support the time squared relationship.

Finally, removal of measurement error and smallscale turbulence allows considerable improvement in regression forecasts, so that relatively simple methods for improving observations should be examined. This paper will show derivations and statistics which led to these various conclusions. A check on these principles will be made for other latitudes, and a so-called "ultimate" regression forecast capability will be applied to some problems of scheduling wind-related operations and predictions of fallout patterns.

\section{Definitions}

To simplify notation and aid understanding, some liberties will be taken with conventional statistical and meteorological notations. The exacting distinction between mean variance and sample mean variance will be neglected by assuming adequately large samples $n$ for each statistic so that $n \approx(n-1)$ and so that $\left(\sum x\right) / n$ is taken as the true expectation of $x$. Complete expressions for statistical summations will be abbreviated so that, for example, the mean value of a variable $x$, is written as

$$
\bar{x}=\frac{1}{n} \sum_{i=1}^{n} x_{i}=\frac{1}{n} \sum x .
$$

Several different deviations and correlation coefficients will be used; these are individually distinguished by numerical subscripts in the succeeding definitions. Other notation will be defined as it is used. The propagation of random variations or errors, $\sigma(x)$ and $\sigma(y)$, in a function $f(x, y)$ is such that

$$
\sigma^{2}(f)=\left(\frac{\partial f}{\partial x}\right)^{2} \sigma^{2}(x)+\left(\frac{\partial f}{\partial y}\right)^{2} \sigma^{2}(y) .
$$

Observed zonal, west to east, and meridional, south to north, components of wind are $(U, V)$, respectively. True wind components, with measurement error removed, are $(u, v)$. Deviations from the mean wind components $(\bar{u}, \bar{v})$ are $\left(u^{\prime}, v^{\prime}\right)$ or $\left(U^{\prime}, V^{\prime}\right)$, assuming that $\bar{u}=\bar{U}$ and $\bar{v}=\bar{V}$ for large $n$. Measurement standard error will be assumed to include effects of small-scale turbulence and be denoted by $m$, so that, for example,

$$
m^{2}=\frac{1}{n} \sum(U-u)^{2} .
$$

Standard deviation of the true component wind $\sigma_{1}$, expressed as a mean variance, is distinguished by sub-

\footnotetext{
${ }^{8}$ Buell, C. E., 1962: Two-point variability of the wind. Kaman Nuclear Report, KN-173-62-2(FR), 3 volumes (also AFCRL, 62-889), Colorado Springs, Colo.
} 
script 1, so

$$
\sigma_{1}^{2}=\frac{1}{n} \sum u^{\prime 2}=\frac{1}{n} \sum u^{2}-\bar{u}^{2}
$$

Variance of an observed wind component is subscripted by 2 , so that

$$
\sigma_{2}{ }^{2}=\frac{1}{n} \sum U^{\prime 2}=\frac{1}{n} \sum U^{2}-\dot{u^{2}}=\sigma_{1}^{2}+m^{2} .
$$

Variance of true wind component changes from $u_{0}$ to $u_{t}$ in a time interval from 0 to $t$, are denoted by

$$
\sigma_{3}^{2}=\frac{1}{n} \sum\left(u_{0}-u_{t}\right)^{2}
$$

while observed changes are described by

$$
\sigma_{4}^{2}=\frac{1}{n} \sum\left(U_{0}-U_{t}\right)^{2}
$$

Correlation coefficients between two variables $(x, y)$ are generally defined by

$$
\rho(x, y)=\left(\frac{1}{n} \sum x^{\prime} y^{\prime}\right) / \sigma(x) \sigma(y),
$$

so for wind components at times $(0, t)$

$$
\begin{aligned}
& \rho_{1}=\left(\sum u_{0}{ }^{\prime} u_{t}^{\prime}\right) / n \sigma_{1}{ }^{2}, \\
& \rho_{2}=\left(\sum U_{0}{ }^{\prime} U_{\imath}^{\prime}\right) / n \sigma_{2}{ }^{2}, \\
& \rho_{3}=\left(\sum U_{0}^{\prime} u_{t}^{\prime}\right) / n \sigma_{1} \sigma_{2} .
\end{aligned}
$$

Standard errors in forecast components will be denoted by $F$, with subscripts defined as used. Standard errors from assuming persistence will be denoted by $P$.

\section{BREEZE wind forecasts and tests}

A statistical zonal wind forecast for observed wind $U_{t}$, at time $t$, based on an optimum linear combination of the latest observation $U_{0}$, at $t=0$, and the climatic mean $\bar{u}$, is

$$
\widetilde{U}_{i}=a U_{0}+(1-a) \bar{u} \text {. }
$$

Derivations are simplified by forecasting only departures from the mean, so that

$$
\text { - } \tilde{U}_{t}^{\prime}=a U_{0}^{\prime} \text {. }
$$

The best value for the proportionality constant gives the minimum error variance, and is derived from defining error $E$ as

$$
E=U_{t}^{\prime}-\tilde{U}_{t}^{\prime}=U_{t}^{\prime}-a U_{0}^{\prime} .
$$

Squared and summed over $n$ cases, this gives

$$
\sum E^{2}=\sum U_{t}^{\prime 2}-2 a \sum U_{0}{ }^{\prime} U_{\imath}^{\prime}+a^{2} \sum U_{0}{ }^{\prime 2},
$$

\begin{tabular}{|c|c|c|c|c|c|c|c|c|c|c|c|}
\hline \multirow{2}{*}{\multicolumn{2}{|c|}{$u$-component }} & \multirow[b]{2}{*}{0} & \multirow[b]{2}{*}{10} & \multirow[b]{2}{*}{20} & \multirow{2}{*}{30} & \multicolumn{2}{|c|}{$\begin{array}{l}\text { Altitude } \\
\text { (kilofeet) }\end{array}$} & \multirow{2}{*}{60} & \multirow[b]{2}{*}{70} & \multirow[b]{2}{*}{80} & \multirow[b]{2}{*}{90} \\
\hline & & & & & & 40 & 50 & & & & \\
\hline \multirow{3}{*}{ 6-hr } & $\sigma_{2}$ & 4.4 & 7.0 & 8.4 & 13.5 & 20.3 & 17.1 & 16.3 & 16.2 & 15.7 & 16.3 \\
\hline & $\rho_{2}$ & 0.566 & 0.658 & 0.729 & 0.814 & 0.880 & 0.788 & 0.782 & 0.771 & 0.604 & 0.571 \\
\hline & $F_{b}$ & 3.6 & 5.2 & 5.7 & 7.9 & 9.7 & 10.5 & 10.2 & 10.3 & 12.5 & 13.4 \\
\hline \multirow[t]{2}{*}{ 12-hr } & $\rho_{2}$ & 0.466 & 0.488 & 0.632 & 0.717 & 0.830 & 0.760 & 0.790 & 0.752 & 0.564 & 0.414 \\
\hline & $F_{b}$ & 3.9 & 6.1 & 6.5 & 9.4 & 11.3 & 11.1 & 10.0 & 10.7 & 13.0 & 14.8 \\
\hline \multirow[t]{2}{*}{ 18-hr } & $\rho_{2}$ & 0.414 & 0.419 & 0.535 & 0.678 & 0.770 & 0.676 & 0.786 & 0.735 & 0.570 & 0.505 \\
\hline & $F_{b}$ & 4.0 & 6.4 & 7.1 & 10.0 & 13.0 & 12.6 & 10.1 & 11.0 & 12.9 & 14.1 \\
\hline \multirow{2}{*}{ 24-hr } & $\rho_{2}$ & 0.406 & 0,312 & 0.489 & 0.564 & 0.710 & 0.654 & 0.756 & 0.718 & 0.524 & 0.524 \\
\hline & $F_{b}$ & 4.0 & 6.6 & 7.3 & 10.5 & 14.3 & 12.9 & 10.6 & 11.2 & 13.4 & 14.0 \\
\hline \multirow[t]{2}{*}{ 48-hr } & $\rho_{2}$ & 0.244 & 0.130 & 0.265 & 0.453 & 0.548 & 0.518 & 0.782 & 0.748 & 0.560 & 0.346 \\
\hline & $F_{b}$ & 4.3 & 6.9 & 8.1 & 12.1 & 17.0 & 14.6 & 10.2 & 10.8 & 13.0 & 15.4 \\
\hline \multicolumn{12}{|c|}{$v$-component } \\
\hline \multirow{3}{*}{ 6-ht } & $\sigma_{2}$ & 4.7 & 5.4 & 6.9 & 9.4 & 15.2 & 14.1 & 6.8 & 6.5 & 7.7 & 8.4 \\
\hline & $\rho_{2}$ & 0.560 & 0.429 & 0.660 & 0.635 & 0.778 & 0.608 & 0.310 & 0.140 & 0.046 & 0.157 \\
\hline & $F_{b}$ & 3.9 & 4.9 & 5.2 & 7.3 & 9.6 & 11.2 & 6.4 & 6.4 & 7.7 & 8.2 \\
\hline \multirow[t]{2}{*}{ 12-hr } & $\rho_{2}$ & 0.380 & 0.187 & 0.450 & 0.566 & 0.668 & 0.502 & 0.128 & 0.000 & -0.095 & -0.015 \\
\hline & $F_{b}$ & 4.3 & 5.3 & 6.1 & 9.0 & 11.4 & 12.2 & 6.5 & 6.5 & 8.0 & 8.4 \\
\hline \multirow[t]{2}{*}{ 18-hr } & $\rho_{2}$ & 0.342 & -0.050 & 0.302 & 0.501 & 0.536 & 0.430 & 0.148 & -0.072 & -0.030 & -0.002 \\
\hline & $\tilde{F}_{b}$ & 4.4 & 5.4 & 6.6 & 9.5 & 12.9 & 12.7 & 6.7 & 6.5 & 8.1 & 7.7 \\
\hline \multirow[t]{2}{*}{ 24-hr } & $\rho_{2}$ & 0.342 & -0.220 & 0.220 & 0.378 & 0.429 & 0.400 & 0.138 & -0.055 & -0.200 & 0.000 \\
\hline & $F_{b}$ & 4.4 & 5.3 & 6.7 & 10.2 & 13.8 & 12.9 & 6.7 & 6.5 & 7.9 & 7.7 \\
\hline \multirow[t]{2}{*}{$48-\mathrm{hr}$} & $\rho_{2}$ & 0.280 & -0.405 & -0.075 & 0.060 & 0.117 & 0.212 & 0.150 & 0.020 & -0.120 & 0.041 \\
\hline & $F_{b}$ & 4.5 & 5.2 & 6.9 & 10.9 & 15.1 & 13.7 & 6.8 & 6.5 & 8.0 & 8.4 \\
\hline
\end{tabular}

which is minimized when

$$
\begin{aligned}
\frac{\partial\left(\sum E^{2}\right)}{\partial a} & =0=-\sum U_{0}{ }^{\prime} U_{t}{ }^{\prime}+a \sum U_{0}{ }^{\prime 2} \\
a & =\left(\sum U_{0}{ }^{\prime} U_{\iota}{ }^{\prime}\right) /\left(\sum U_{0}{ }^{\prime 2}\right)=\rho_{2} .
\end{aligned}
$$

Thus, deviations and winds are forecast to be

$$
\begin{aligned}
& \tilde{U}_{l^{\prime}}=U_{0}{ }^{\prime} \rho_{2} \\
& \widetilde{U}_{t}=U_{0} \rho_{2}+\left(1-\rho_{2}\right) \bar{u} .
\end{aligned}
$$

Forecast standard error $F_{b}$ for this BREEZE regression

TABLE 1. Eniwetok wind statistics, 1956 (winds in knots). 
formula is found from

$$
F_{b}{ }^{2}=\frac{1}{n} \sum E^{2}=\sigma_{2}{ }^{2}-2 \rho_{2}{ }^{2} \sigma_{2}{ }^{2}+\rho_{2}{ }^{2} \sigma_{2}{ }^{2}=\sigma_{2}{ }^{2}\left(1-\rho_{2}^{2}\right)
$$

Upper wind observations made at Eniwetok by Joint Task Force Seven ${ }^{9}$ during Operation Redwing were used to obtain numerical values of $u$ - and $v$-component statistics of $\sigma_{2}, \rho_{2}, \bar{u}$ and $\bar{v}$ for each 10,000 -ft level from the surface to $90,000 \mathrm{ft}$ MSL. Correlation coefficients $\rho_{2}$ were evaluated for time intervals of $6,12,18,24$, and $48 \mathrm{hr}$. Results, with calculated values of $F_{b}$ are shown in Table 1. Data sample sizes ranged from 383 balloon ascensions at $10,000 \mathrm{ft}, 368$ observations at $50,000 \mathrm{ft}$, to 264 which reached $90,000 \mathrm{ft}$. About the same number of comparisons were made for each time lag inter$\mathrm{val}$; they numbered about 365 at $10,000 \mathrm{ft}, 340$ at $50,000 \mathrm{ft}$, and 175 at $90,000 \mathrm{ft}$.

These statistics were used by Reed $^{10}$ to produce upper wind BREEZE computer program forecasts for Operation Hardtack nuclear test fallout predictions. Verifications for vector standard errors were compared with results obtained by the Joint Task Force Seven Meteorological Center for 42 forecasts distributed for test event briefings. Results showed that BREEZE predictions were superior at most levels but became significantly inferior at 80,000 and $90,000 \mathrm{ft}$ as shown in Fig. 1. Persistence was better than BREEZE at 20,000 and $30,000 \mathrm{ft}$ because, apparently, 1956 statistics were not entirely valid during the independent 1958 sampling. At high altitudes Meteorological Center forecasts were made almost entirely from climatology. Their relative performance indicated that observation errors at these levels were so large, compared to real wind deviations from the mean, that large errors were induced in BREEZE by use of an initial wind observation.

An attempt was made to refine BREEZE predictions by using observation data gathered $6 \mathrm{hr}$ previous to forecast time and adding a term to the linear regression equation. For zonal component forecasts for deviations,

$$
\widetilde{U}_{t}^{\prime}=a U_{0}{ }^{\prime}+b U_{6}^{\prime},
$$

approximation errors squared and summed give

$$
\begin{aligned}
\sum E^{2}= & \sum U_{t}{ }^{2}+a^{2} \sum U_{0}{ }^{2} \\
& +b^{2} \sum U_{6}{ }^{2}-2 a \sum U_{t}^{\prime} U_{0}{ }^{\prime} \\
& -2 b \sum U_{t}^{\prime} U_{6}{ }^{\prime}+2 a b \sum U_{0}{ }^{\prime} U_{6}{ }^{\prime} .
\end{aligned}
$$

Minimizing by setting

$$
\partial\left[\sum E^{2}\right] / \partial a=\partial\left[\sum E^{2}\right] / \partial b=0
$$

Joint Task Force Seven, 1956: Meteorological report on Operation Redwing, Part 1, Vol. 1. JTF-7 Meteorological Center, Pearl Harbor, Hawaii.

${ }^{10}$ Reed, J. W., op. cit.

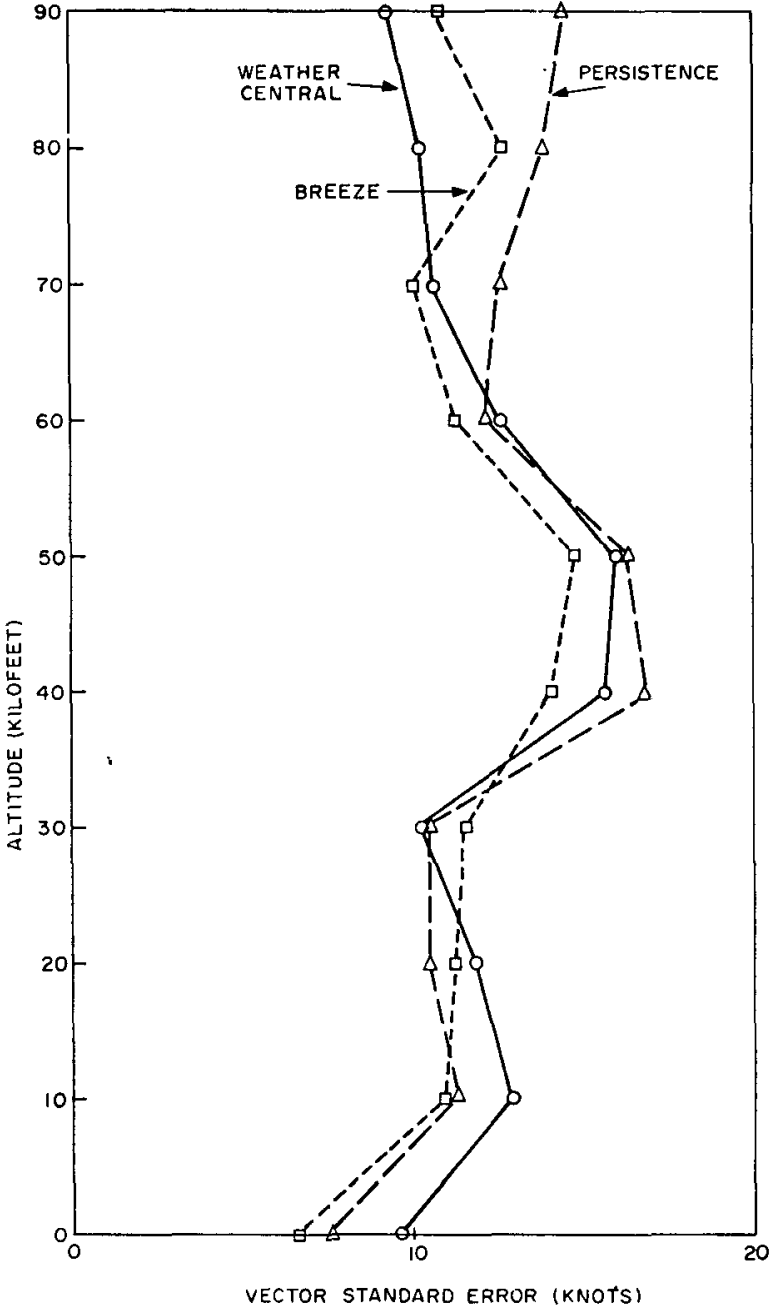

Fig. 1. Wind forecast verifications, 1958 Operation Hardtack.

gives best values for $a$ and $b$,

$$
\begin{aligned}
& a=\left(\rho_{0 t}-\rho_{06} \rho_{6 t}\right) /\left(1-\rho_{06}{ }^{2}\right), \\
& b=\left(\rho_{6 t}-\rho_{06} \rho_{0 t}\right) /\left(1-\rho_{06}{ }^{2}\right),
\end{aligned}
$$

where, as previously defined

$$
\rho_{2}=\rho_{0 t}=\left(\sum U_{0}^{\prime} U_{\imath}^{\prime}\right) / n \sigma_{2}{ }^{2},
$$

and, in addition,

$$
\begin{aligned}
& \rho_{06}=\left(\sum U_{0}{ }^{\prime} U_{6}{ }^{\prime}\right) / n \sigma_{2}{ }^{2}, \\
& \rho_{6 t}=\left(\sum U_{6}{ }^{\prime} U_{t}{ }^{\prime}\right) / n \sigma_{2}{ }^{2} .
\end{aligned}
$$

Forecast error $F_{2 b}$ for this new regression is found from the variance

$$
F_{2 b}{ }^{2}=\sigma_{2}{ }^{2}\left[1-\frac{\rho_{0 t}{ }^{2}+\rho_{6 t}{ }^{2}-2 \rho_{0 t} \rho_{6 t} \rho_{06}}{1-\rho_{06}{ }^{2}}\right] .
$$

Calculation of $u$-component forecast errors showed that two-term regressions gave only small, practically 


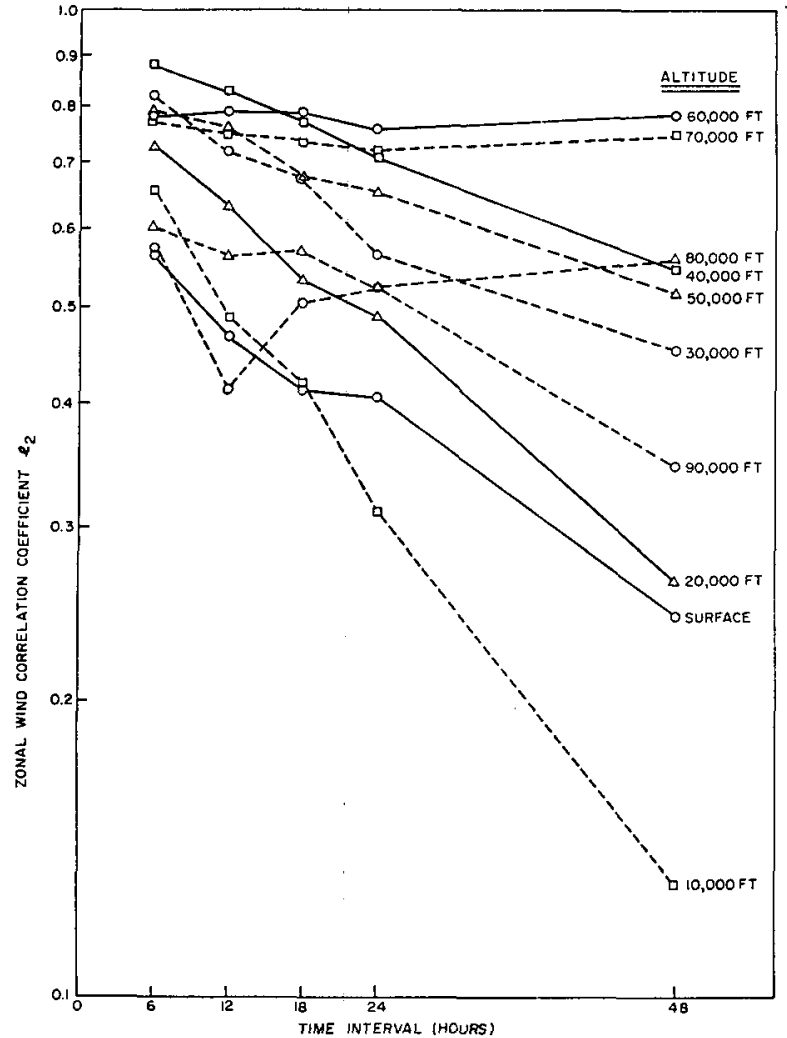

FIG. 2. Time-lag correlation coefficient decay, observed zonal winds.

insignificant improvement over one-term linear regression forecasts. This condition, $F_{b} \approx F_{2 b}$, is satisfied when $\rho_{6 t}=\rho_{0 t} \rho_{06}$ and the correlation coefficient decays exponentially with time interval, that is, $\rho_{0 t}=e^{-k t}$.

Correlation coefficients for $u$-component winds, listed in Table 1, were plotted in semi-logarithmic coordinates in Fig. 2. Some typical standard errors in estimating correlation coefficients are shown in Table 2. Occasional negative values for meridional or $v$-component correlation coefficients require Cartesian coordinate plotting, shown in Fig. 3. Meridional correlation decay is not exponential, but it also does not clearly show cyclic oscillation which might be expected from synoptic scale waves with periods of a few days. A calculation for longer periods would be needed to fully determine the meridional decay function.

Zonal component correlation decay, however, is nearly exponential (after $6 \mathrm{hr}$ ) at every level except at

TABLE 2. Sample size and standard errors in estimating zonal wind time-lag correlation coefficients for representative altitudes.

\begin{tabular}{ccccccc}
\hline \hline \multirow{2}{*}{$\begin{array}{c}\text { Time } \\
\text { interval }\end{array}$} & \multicolumn{2}{c}{$10,000 \mathrm{ft}$} & \multicolumn{2}{c}{$50,000 \mathrm{ft}$} & \multicolumn{2}{c}{$90,000 \mathrm{ft}$} \\
(hours) & S.E. $(\rho)$ & $N$ & S.E. $(\rho)$ & $N$ & S.E. $(\rho)$ & $N$ \\
\hline 6 & 0.030 & 368 & 0.020 & 341 & 0.050 & 184 \\
24 & 0.047 & 365 & 0.031 & 337 & 0.055 & 176 \\
48 & 0.052 & 360 & 0.040 & 336 & 0.066 & 181 \\
\hline
\end{tabular}

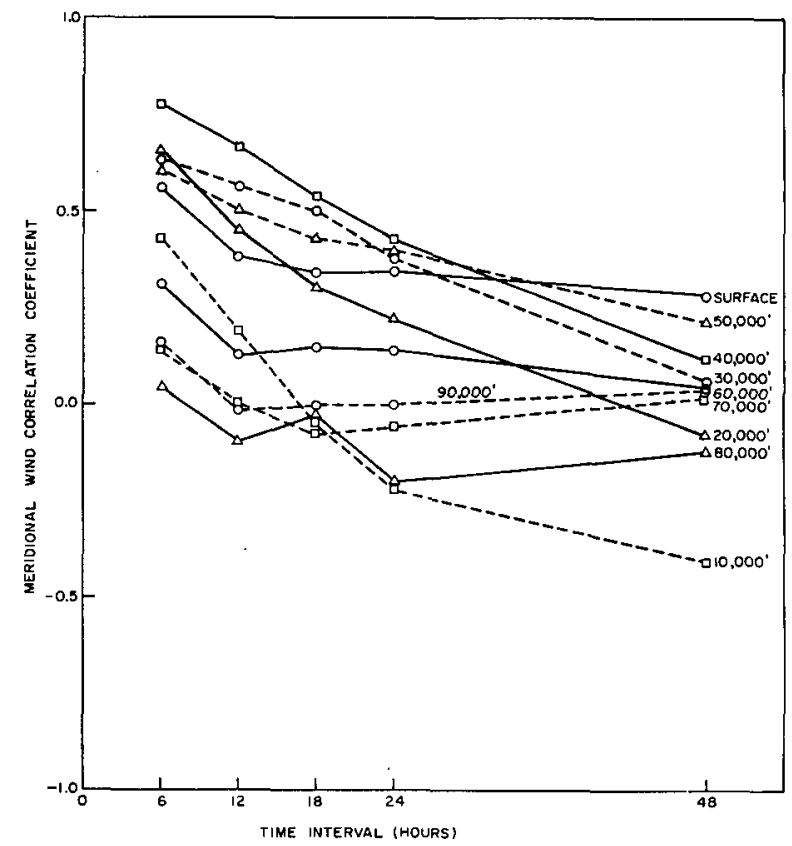

FIG. 3. Time-lag correlation coefficient decay, observed meridional winds.

high altitudes where less confidence is placed in relatively inaccurate observations. The more rapid decay during initial 6-hr periods may be attributed partly to observing error, and partly to effects from small scale turbulence.

Previous data assembled by Reed ${ }^{11}$ [see also Reed (1954)] showed that wind change standard deviations increased in proportion to the square root of the time interval. This is not inconsistent with the exponential decay of correlation coefficient model. Variance of wind with time,

$$
\sigma_{4}^{2}=\frac{1}{n} \sum\left(U_{0}^{\prime}-U_{i}^{\prime}\right)^{2}
$$

in expanded form

$$
\sigma_{4}^{2}=\frac{1}{n} \sum U_{0}^{\prime 2}-\frac{2}{n} \sum U_{0}^{\prime} U_{t}^{\prime}+\frac{1}{n} \sum U_{t}^{\prime 2},
$$

leads to

$$
\sigma_{4}^{2}=2 \sigma_{2}^{2}\left(1-\rho_{2}\right)
$$

If $\rho_{2} \approx e^{-k t}$, series expansion of $e^{-k t}$ gives

$$
\begin{aligned}
\sigma_{4}^{2} & =2 \sigma_{2}^{2}\left\{1-\left[1-k t+\frac{(k t)^{2}}{2 !}-\frac{(k l)^{3}}{3 !}+\cdots\right]\right\} \\
& =2 \sigma_{2}{ }^{2} k t\left[1-\frac{k t}{2 !}+\frac{(k t)^{2}}{3 !}-\cdots\right] .
\end{aligned}
$$

11 Reed, J. W., 1958: A study of Nevada test site wind variability. Sandia Corporation Report SC-4144(TR), Albuquerque, N. Mex., 56 pp. 
TABLE 3. Derived measurement errors and extrapolated zero-time correlations.

\begin{tabular}{ccc}
\hline $\begin{array}{c}\text { Altitude } \\
\text { (kilofeet) }\end{array}$ & $\begin{array}{c}\text { Estimated } \\
r\end{array}$ & $\begin{array}{c}\text { Measurement } \\
\text { error } m \\
(\mathrm{kt})\end{array}$ \\
\hline 0 & 0.607 & 2.8 \\
10 & 0.804 & 3.1 \\
20 & 0.839 & 3.4 \\
30 & 0.842 & 5.4 \\
40 & 0.944 & 4.8 \\
50 & 0.834 & 7.0 \\
60 & 0.781 & 8.6 \\
70 & 0.754 & 10.1 \\
80 & 0.581 & 10.7 \\
90 & 0.569 & \\
\hline
\end{tabular}

For reasonably large decay times $k^{-1}$, it is clear that the approximation $\sigma_{4} \sim t^{\frac{1}{2}}$ is reasonable.

In summary, zonal wind time-lag correlations decay nearly exponentially so that a prediction based on the latest observation cannot be improved in the linear model by addition of prior data. Three indicators, two substantial and one minor, point to a combination of measurement inaccuracy and small scale turbulence as a major source of statistical forecasting errors. At high altitudes, climatology may give better forecasts than objective statistics; at all levels, zonal time-lag correlation decays rapidly for the first $6 \mathrm{hr}$, then assumes a nearly constant exponential rate until at least $48 \mathrm{hr}$; and finally, most high altitude statistics are erratic, as expected from measurement error at generally longer balloon ranges from observing equipment.

Since there are many differing opinions on winds aloft measurement errors ${ }^{12}$ and since it is impossible to obtain an on-the-spot calibration of the equipment used to obtain the Eniwetok data sample, an indirect error assessment, from the data itself, seems to be the best course to follow in forecast refinement.

\section{Measurement error analysis}

The exponential decay of correlation with increasing time interval may be used to estimate measurement error. Since

$$
\rho_{0 t}=\frac{\sum U_{0}^{\prime} U_{t}^{\prime}}{n \sigma_{2}^{2}} \approx r e^{-k t},
$$

and

$$
U_{i}{ }^{\prime}=u_{i}{ }^{\prime}+m_{i},
$$

where $m$ is measurement error,

$$
\rho_{0 t}=\frac{\sum\left(u_{0}^{\prime}+m_{0}\right)\left(u_{t}^{\prime}+m_{t}\right)}{n \sigma_{2}{ }^{2}}=\frac{u_{0}^{\prime} u_{t}^{\prime}}{n \sigma_{2}{ }^{2}},
$$

where, since $m$ is random with zero mean,

$$
\sum m_{0} u_{t}^{\prime}=\sum m_{t} u_{0}^{\prime}=\sum m_{0} m_{t}=0 .
$$

12 Meteorological equipment data accuracies. IRIG Document 110-64, Meteorological Working Group, Inter-Range Instrumentation Group; Secretariat, Range Commander Council, White Sands Missile Range, N. Mex., March 1965.

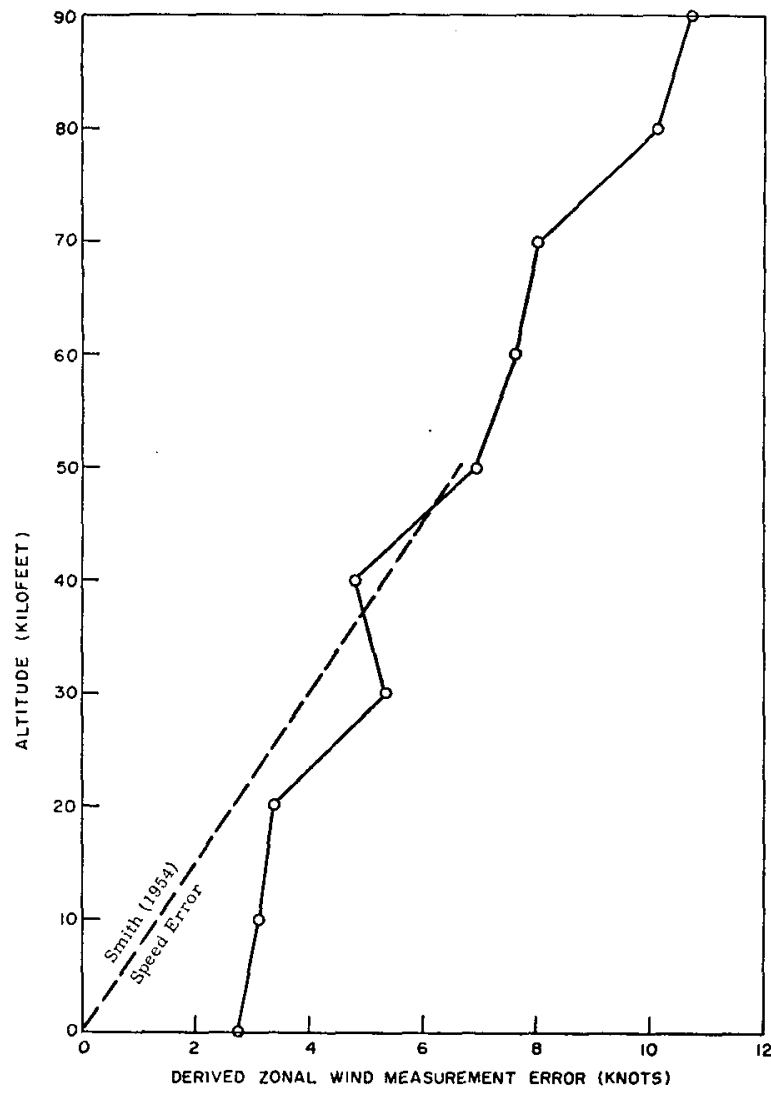

FIG. 4. Derived measurement error for zonal wind components.

Extension of $\sigma_{0 t}$ to $t=0$ shows

$$
\lim _{t \rightarrow 0} \sigma_{0 t}=\lim _{t \rightarrow 0}\left(\frac{\sum u_{0}^{\prime} u_{t}^{\prime}}{n \sigma_{2}^{2}}\right)=\frac{\sigma_{1}^{2}}{\sigma_{2}^{2}}=r
$$

which may be estimated from data shown in Fig. 2. Then, since

$$
\begin{aligned}
r \sigma_{2}{ }^{2} & =\sigma_{1}{ }^{2}=\sigma_{2}{ }^{2}-m^{2}, \\
m^{2} & =\sigma_{2}{ }^{2}(1-r) .
\end{aligned}
$$

Root-mean-square linear extrapolations from curves in Fig. 2 provide values for $r$ and $m$ shown in Table 3 . Measurement error, thus derived, is shown versus altitude in Fig. 4. In general, error estimates seem reasonable when compared with other evaluations such as performed by $\mathrm{Smith}^{13}$ and by Rapp (1952).

Comparison to standard deviations found in differences between observed winds and estimated geostrophic winds is interesting. Some manipulation of Kays (1966) statistics table leads to a standard deviation for the ageostrophic zonal wind component of about $14 \mathrm{kt}$ at $10 \mathrm{mb}$ pressure, near 102,000-ft altitude. Godson (1950) also reported ageostrophic components

${ }^{13}$ Smith, L. B., 1954: A study comparing winds aloft measuring equipment at Salton Sea Test Base. Sandia Corporation Report SC-3512(TR), Albuquerque, N. Mex., 15 pp. 


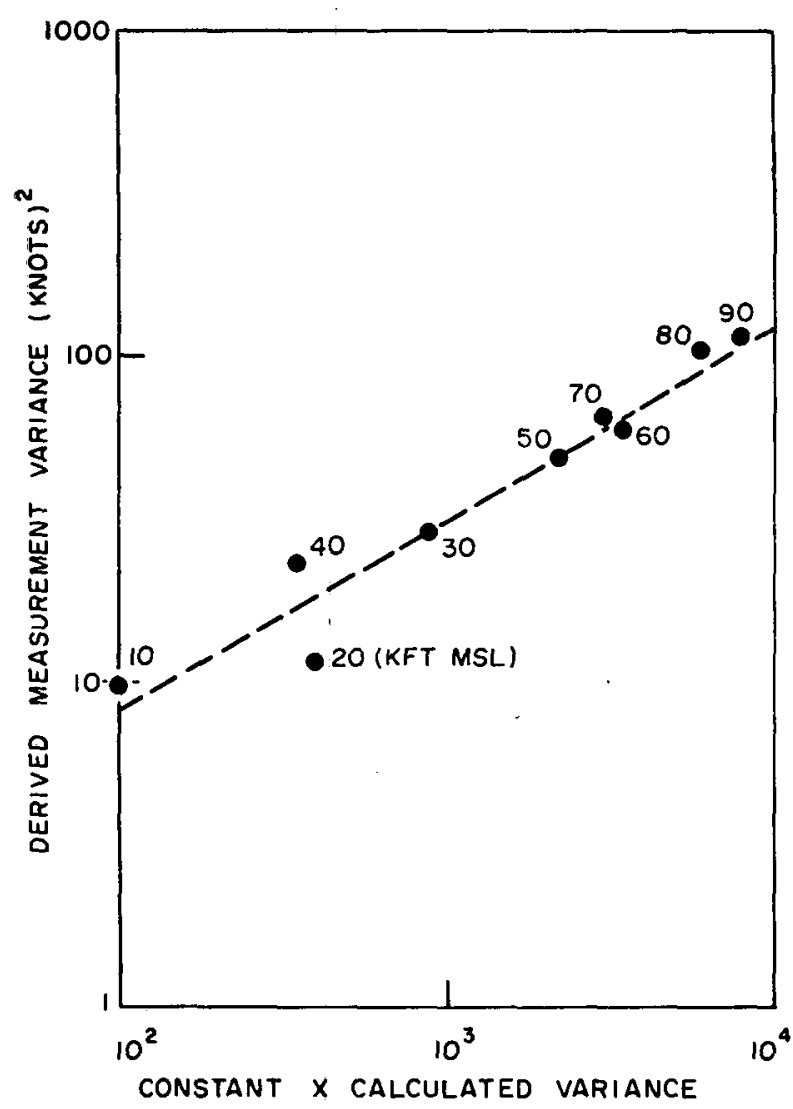

FIG. 5. Derived vs. computed measurement error comparisons.

at $10,000 \mathrm{ft}$ that were $2-3 \mathrm{kt}$ greater than shown in Fig. 4. Bannon (1949), however, found ageostrophic departures at $500 \mathrm{mb}$, or $18,000 \mathrm{ft}$, which were near $10 \mathrm{kt}$ in the zonal component, which seems excessive. The $2-3 \mathrm{kt}$ difference value is easily acceptable, probably representing the map analysis and geostrophic wind calculation component of the total ageostrophic departure.

A further check, comparing error with position and orientation, was made using techniques described by Reed and VanZandt ${ }^{14}$ to show derived measurement variance versus a variance based on mean balloon position. Results, plotted in Fig. 5, do not show linear proportionality but a power law relationship. Thus, they do show that error analyses for radar winds are not applicable. At least three factors besides the assumption of mean balloon position may have influenced the fact that error does not increase in linear proportions to calculated variance: a combination of radiosonde pressure altitude error effects which were not considered, different smoothing procedures and longer time intervals between position calculations at high altitudes, and finally, effects of small scale turbulence. A suitable and generally acceptable derivation for errors in routine rawinsonde winds is not known. ${ }^{15}$

${ }^{14}$ Reed, J. W., and T. E. VanZandt, 1957: Wind and position variability from Rawijet data. Sandia Corporation Technical Memorandum SCTM-61-57-51, Albuquerque, N. Mex., 25 pp.

${ }_{15}$ Meteorological equipment data accuracies. Loc. cit.
Derived measurement errors were, therefore, assumed to be about correct and the best available for present purposes. Their variances were removed from the observed data collection. This method follows from the propagation of random variance where

$$
\frac{1}{n} \sum\left(U_{t}^{\prime}-U_{0}^{\prime}\right)^{2}=\frac{1}{n} \sum\left(u_{t}^{\prime}-u_{0}{ }^{\prime}\right)^{2}+2 m^{2} .
$$

Expanding gives

$$
\begin{aligned}
\frac{1}{n} \sum U_{t}{ }^{\prime 2} & -\frac{2}{n} \sum U_{t}{ }^{\prime} U_{0}{ }^{\prime}+\frac{1}{n} \sum U_{0}{ }^{2} \\
& =\frac{1}{n} \sum u_{t}^{\prime 2}-\frac{2}{n} \sum u_{t}^{\prime} u_{0}{ }^{\prime}+\frac{1}{n} \sum u_{0}{ }^{2}+2 n^{2},
\end{aligned}
$$

so that on dividing by 2

$$
\sigma_{2}^{2}-\sigma_{2}^{2} \rho_{2}=\sigma_{1}^{2}-\sigma_{1}^{2} \rho_{1}+m^{2} .
$$

Since $\sigma_{1}{ }^{2}=\sigma_{2}{ }^{2}-m^{2}$, the corrected true correlation coefficient is

$$
\rho_{1}=\frac{\sigma_{2}^{2} \rho_{2}}{\sigma_{2}^{2}-m^{2}} .
$$

Corrected values for $\rho_{1}$ and $\sigma_{1}$ are listed in Table 4 . Time-lag correlation coefficients $\rho_{1}$ are plotted in Fig. 6

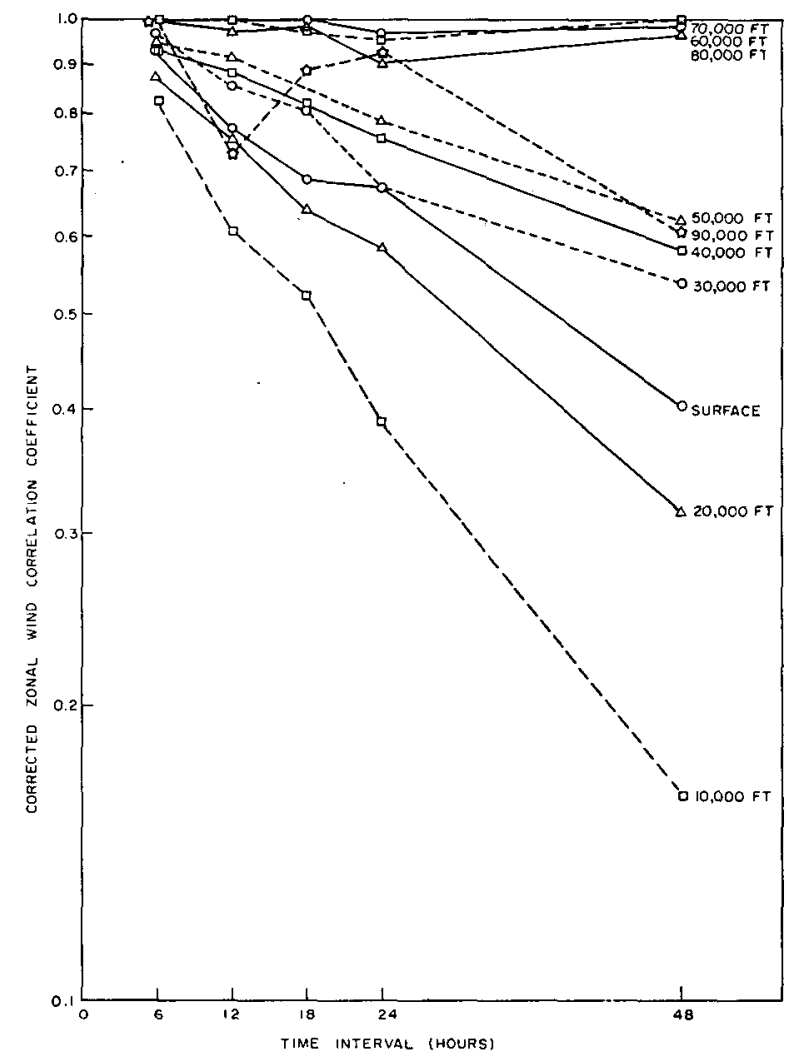

Fig. 6. Corrected zonal wind time-lag correlation coefficients. 
TABLE 4. Eniwetok true wind statistics, corrected for derived measurement error.

\begin{tabular}{|c|c|c|c|c|c|c|c|c|c|c|c|}
\hline \multirow{2}{*}{\multicolumn{2}{|c|}{$u$-component }} & \multicolumn{10}{|c|}{$\begin{array}{l}\text { Altitude } \\
\text { (kilofeet) }\end{array}$} \\
\hline & & 0 & 10 & 20 & 30 & 40 & 50 & 60 & 70 & 80 & 90 \\
\hline \multirow{4}{*}{ 6-hr } & $\sigma_{1}$ & 3.4 & 6.3 & 7.7 & 12.4 & 19.7 & 15.6 & 14.4 & 14.1 & 11.9 & 12.3 \\
\hline & $\rho_{1}$ & 0.935 & 0.820 & 0.868 & 0.967 & 0.933 & 0.946 & 0.999 & 0.999 & 0.999 & 0.999 \\
\hline & $F_{u}$ & 1.2 & 3.6 & 3.8 & 3.2 & 7.1 & 5.0 & 0.6 & 0.6 & 0.5 & 0.6 \\
\hline & $P_{t}$ & 1.2 & 3.8 & 4.0 & 3.2 & 7.2 & 5.1 & 0.6 & 0.6 & 0.5 & 0.6 \\
\hline \multirow[t]{3}{*}{$12-\mathrm{hr}$} & $\rho_{1}$ & 0.771 & 0.608 & 0.753 & 0.852 & 0.880 & 0.912 & 0.999 & 0.997 & 0.971 & 0.728 \\
\hline & $F_{u}$ & 2.2 & 5.0 & 5.1 & 6.5 & 9.4 & 6.4 & 0.6 & 1.1 & 2.9 & 7.5 \\
\hline & $P_{i}$ & 2.3 & 5.6 & 5.4 & 6.7 & 9.7 & 6.6 & 0.6 & 1.1 & 2.7 & 9.1 \\
\hline \multirow[t]{3}{*}{ 18-hr } & $\rho_{1}$ & 0.684 & 0.521 & 0.637 & 0.805 & 0.816 & 0.811 & 0.999 & 0.975 & 0.982 & 0.888 \\
\hline & $F_{u}$ & 2.5 & 5.4 & 5.9 & 7.4 & 11.4 & 9.1 & 0.6 & 3.1 & 2.3 & 5.7 \\
\hline & $P_{t}^{a}$ & 2.7 & 6.1 & 6.6 & 7.7 & 12.0 & 9.6 & 0.6 & 3.2 & 2.3 & 5.8 \\
\hline \multirow[t]{3}{*}{ 24-hr } & $\rho_{1}$ & 0.671 & 0.388 & 0.582 & 0.670 & 0.753 & 0.785 & 0.968 & 0.952 & 0.902 & 0.922 \\
\hline & $F_{u}$ & 2.5 & 5.8 & 6.3 & 9.2 & 13.0 & 9.7 & 3.6 & 4.3 & 5.1 & 4.8 \\
\hline & $P_{t}^{a}$ & 2.8 & 6.9 & 7.0 & 10.1 & 13.9 & 10.2 & 3.6 & 4.4 & 5.3 & 4.9 \\
\hline \multirow[t]{3}{*}{$48-\mathrm{hr}$} & $\rho_{1}$ & 0.403 & 0.162 & 0.315 & 0.538 & 0.581 & 0.622 & 0.989 & 0.992 & 0.964 & 0.608 \\
\hline & $F_{u}$ & 3.1 & 6.2 & 7.3 & 10.4 & 16.1 & 12.2 & 2.1 & 1.8 & 3.2 & 9.8 \\
\hline & $P_{t}$ & 3.8 & 8.1 & 9.0 & 11.9 & 18.1 & 13.6 & 2.1 & 1.8 & 3.2 & 10.9 \\
\hline
\end{tabular}

which shows at most levels there is quite regular exponential decay from near unity at $t=0$. Points at $90,000 \mathrm{ft}$ are quite erratic and probably should be disregarded. One notable feature is that maximum time decay rate occurs at $10,000 \mathrm{ft}$, near the middle of trade wind flow and about the middle altitude of many turbulent cumulus clouds.

Correlation decay rates decrease with increased altitude up to tropopause levels of $40-50,000 \mathrm{ft}$. Above the tropopause, at $60,000 \mathrm{ft}$ and higher, correlation coefficients are all very nearly 1 . This means that, on these time scales, zonal wind is tremendously persistent. Lacking a longer wavelength source, there may be no eddy energy to be converted into small scale eddies and turbulence. Carrying this speculation further indicates that there may be very small diffusivities in these high layers and there may be no turbulence to affect aircraft. Weinstein $e t$ al. (1966) have shown that inertial oscillations may generate wind shears which could cause turbulence at supersonic transport cruise altitudes. It seems, however, that this must be very rare compared to the encounters with CAT (clear air turbulence) at near tropopause altitudes of subsonic jet operations. If there were much turbulence in the stratosphere caused by inertial oscillations the wind variability and correlation decay rates would be much larger than they are.

In y-components, as previously mentioned, meridional winds do not show the exponential correlation decay, nor do they clearly show a periodic oscillation. An attempt was made to subtract $u$-component measurement errors from $v$-component variances, but above $50,000 \mathrm{ft}$ derived measurement variance exceeded total observed variance. A measurement variance based on a similar function to that in Fig. 5 was calculated, but it, too, exceeded total variance at both 70,000 and $90,000 \mathrm{ft}$. Thus, meridional wind errors apparently cannot be isolated by use of mean balloon location data. Proper error estimation would require calculation for each observation based on actual balloon locations. At this late date this was not feasible. Consequently, further discussion will refer only to $u$-component wind statistics.

Errors in BREEZE prediction include the error of observation in verification. If a real application is made for forecasts, these errors are of no consequence. The real error of forecasting is thus smaller than the error determined by verification. A forecast $\tilde{u}_{t}^{\prime}$, for real wind deviation is best made from

$$
\tilde{u}_{t}{ }^{\prime}=a U_{0^{\prime}}{ }^{\prime}
$$

Following the methods used previously,

$$
\begin{aligned}
\sum E^{2} & =\sum u_{t}{ }^{2}-2 a \sum u_{t}{ }^{\prime} U_{0}{ }^{\prime}+a^{2} \sum U_{0}{ }^{2}, \\
\frac{\partial\left(\sum E^{2}\right)}{\partial a} & =0=-\sum u_{t}^{\prime} U_{0}^{\prime}+a \sum U_{0}^{\prime 2}, \\
a & =\frac{\sigma_{1} \sigma_{2} \sigma_{3}}{\sigma_{2}{ }^{2}}=\rho_{2},
\end{aligned}
$$

the same coefficient as when verification by observation was planned. True forecast error $F_{b}(u)$, however, is only

$$
F_{b}{ }^{2}(u)=\sigma_{2}{ }^{2}\left(1-\rho_{2}^{2}\right)-m^{2}
$$

This same reduction of error variance would apply equally in verifying all other forecasting techniques. Since measurement error has been found to be so significant, the next step is to remove it-a mere hardware problem. Small-scale turbulence components of this error may be removed by averaging several observations. Meanwhile, we may derive and evaluate this ultimate BREEZE forecast.

\section{Ultimate BREEZE forecasts}

If the assumption is continued that measurement errors have been properly evaluated in the previous section and their removal leaves true wind statistics, then the forecast efficiency of an errorless observation regression system may be evaluated. This scheme would 
analyze

$$
\tilde{u}_{t}^{\prime}=a u_{0}{ }^{\prime},
$$

where the regression constant $a$ is again defined by minimizing error variance, i.e.,

$$
\begin{aligned}
\sum E^{2} & =\sum u_{t}^{\prime 2}-2 a \sum u_{t}^{\prime} u_{0}{ }^{\prime}+a^{2} \sum u_{0}{ }^{2}, \\
\frac{\partial\left(\sum E^{2}\right)}{\partial a} & =-\sum u_{t}^{\prime} u_{0}^{\prime}+a \sum u_{0}{ }^{2}=0, \\
a & =\rho_{1}, \\
\tilde{u}_{t}^{\prime} & =\rho_{1} u_{0}^{\prime} .
\end{aligned}
$$

Forecast error variance becomes

$$
F_{u}{ }^{2}=\sigma_{1}^{2}\left(1-\rho_{1}^{2}\right) \text {. }
$$

Comparison with errors in forecasting persistence of true winds is made to determine forecast usefulness. A persistence forecast would err by

so that

$$
E=u_{t}^{\prime}-u_{0}^{\prime}
$$

$$
\sum E^{2}=\sum u_{t}^{\prime 2}-2 \sum u_{0}^{\prime} u_{t}{ }^{\prime}+\sum u_{0}{ }^{2},
$$$$
\text { and }
$$

$$
P_{t}^{2}=2 \sigma_{1}^{2}\left(1-\rho_{1}\right) \text {. }
$$

Comparing of $F_{u}^{2}$ with $P_{t}^{2}$ shows that

$$
F_{u}{ }^{2} / P_{t}{ }^{2}=\left(1+\rho_{1}\right) / 2 \text {, }
$$

so that for $\rho_{1}$ values very nearly unity, there is little improvement accomplished by using a climatology term. Ultimate BREEZE gives maximum improvement with $\rho_{1}=0$, no correlation, but this is a forecast of climatic averages. Clearly, if there is no correlation between sequential observations, a forecast of average conditions would have only half the variance of a persistence forecast. Large errors would be eliminated when a large deviation on one side of the average was followed by a large excursion to the other side of the average.

Eniwetok 1956 data, corrected for measurement error, have been used to calculate $F_{u}$ and $P$ values shown in Table 3. Comparisons for 24 -hr and 48 -hr forecasts are graphed in Figs. 7 and 8. At 6-hr intervals there is little to be gained, a few per cent at best, if calculations were accurate, by modifying a persistence forecast. Twentyfour hour forecasts by BREEZE are 5-15 per cent better than persistence up through 50,000 ft MSL. At high altitudes, persistence is not much improved at either forecast time. Forty-eight hour BREEZE predictions are 10-20 per cent better than persistence at most tropospheric altitudes. A comparison with Fig. 1 Weather Central predictions can be made by dividing vector errors by $2^{\frac{1}{2}}$, and by assuming circular normal error distribution, to give zonal component errors. Except at 30,000 and 40,000 ft, where 1958 variability was smaller than found in the 1956 statistics, a significant improvement is made by even persistence forecasts from accurate observations. Furthermore, the 1958 fore-

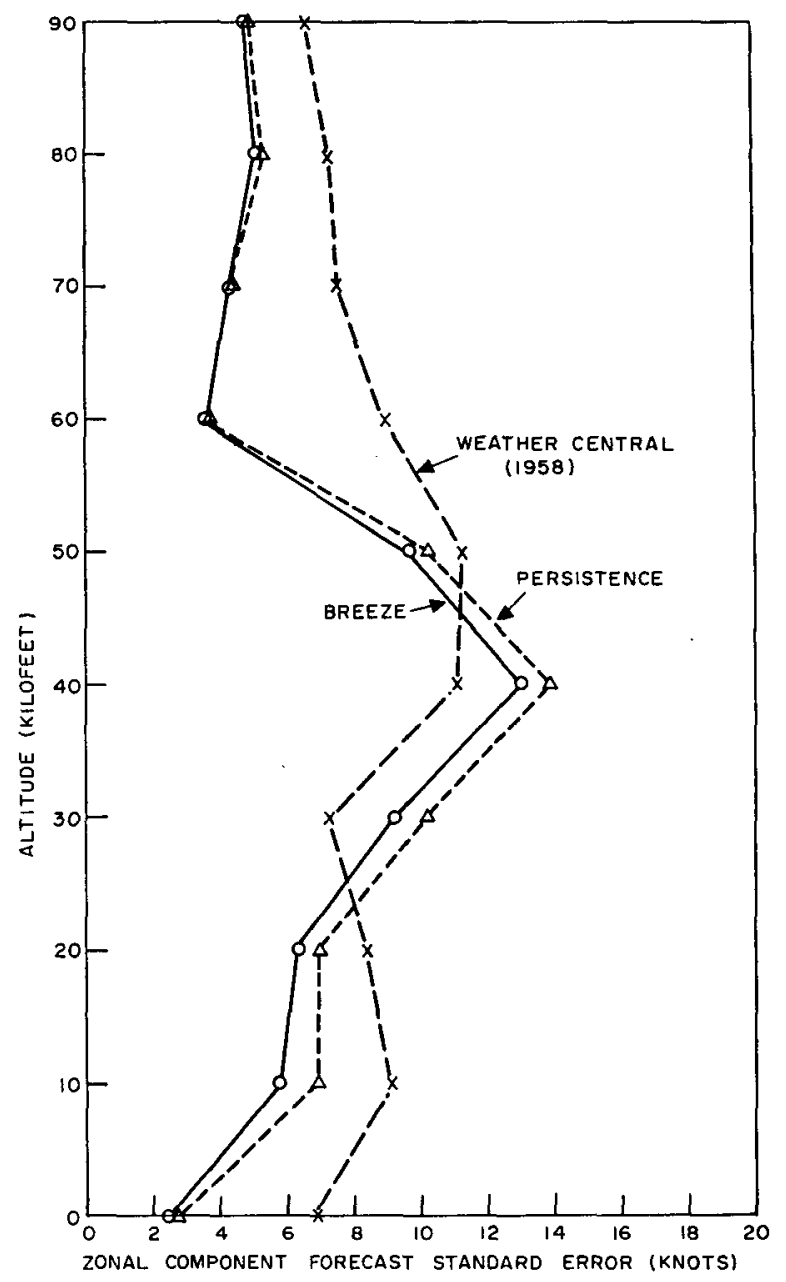

FIG. 7. Errors in 24-hr forecasts by ultimate BREEZE and persistence.

cast sample was not entirely made up of 24-hr forecasts. Most were for less than that time interval and no distinction was kept in records used for this study.

In summary, zonal wind forecasts should be made from accurately observed data. Since applying BREEZE-type forecast coefficients is so simple, it should be done to make best forecasts, although for some altitudes and short time intervals it gains only small improvement over persistence. The net effect is that, at some levels and intervals, wind forecast errors may then be cut by factors of 2 or 3 .

\section{Statistics for other locations}

It has occasionally been argued that statistical forecasts should perform well in the tropics, in a convective turbulent regime, and where winds are not well governed by the geostrophic wind equation. Statistical forecasts should certainly not compete with synoptic or numerical hydrodynamic forecasts at higher latitudes. This contention has been checked using statistics for a 5-yr 


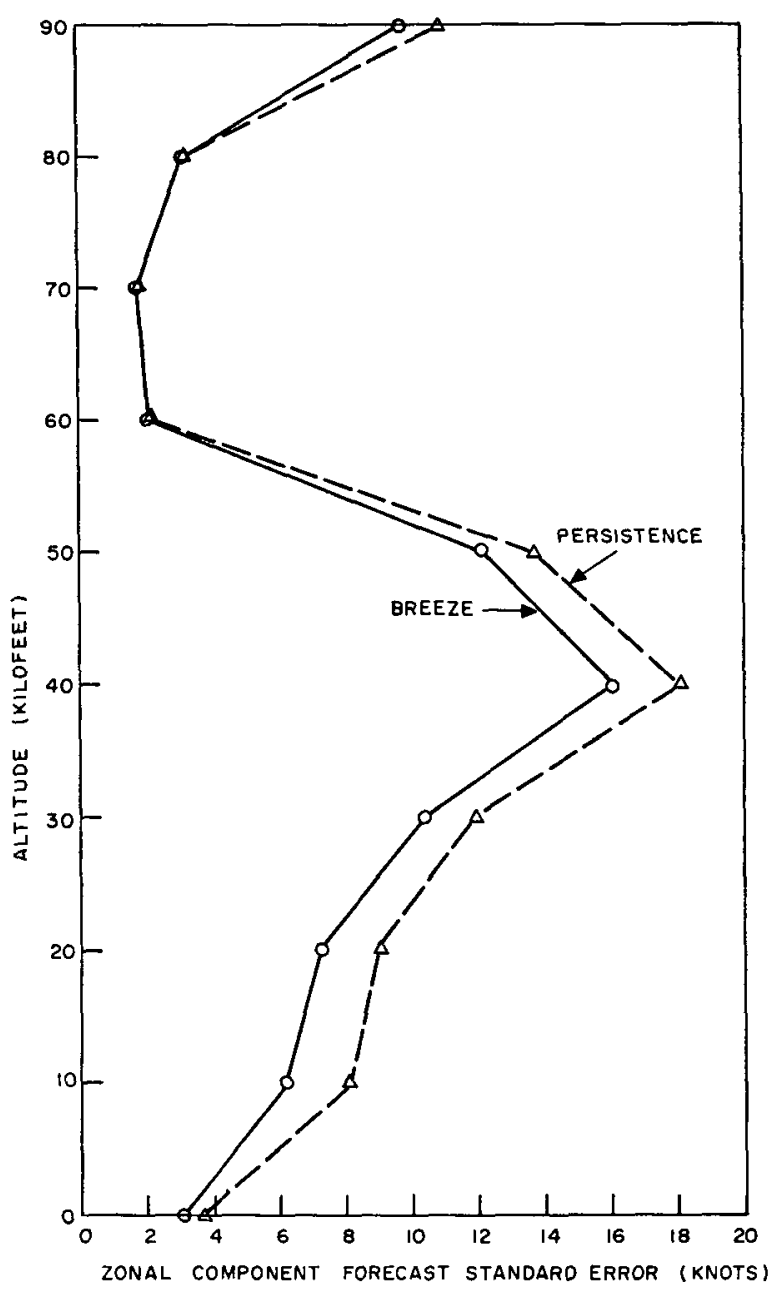

FIG. 8. Errors in 48-hr forecasts by ultimate BREEZE and persistence.

period developed by Charles $^{16}$ in the U. S. Weather Bureau Sandia Corporation Cooperative Project in Climatology, for Nome, Alaska, Ely, Nevada, and Albrook AFB, Canal Zone. There are data for 50 other stations but these three seem representative of most conditions. In view of the general difficulty that has been encountered in making forecasts significantly more accurate than found by assuming persistence of observations, it has been found that regression forecasts, based on corrected observations do give significant improvement over persistence of ordinary inaccurate observations at all stations.

Time-lag correlation coefficients are given for one and two days lag in the Cooperative Project data. Nome, Alaska, values are plotted in Fig. 9, for the four seasons and for nine pressure surfaces. Correlation decays with time were extrapolated back to zero time-lag and

${ }^{16}$ Charles, B. N., 1960: Upper wind statistics from USWBFCDA data. Vol. 2, Interlevel wind correlations. U. S. Weather Bureau-Sandia Corporation Cooperative Project in Climatology (unpublished tabulations), Albuquerque, N. Mex.

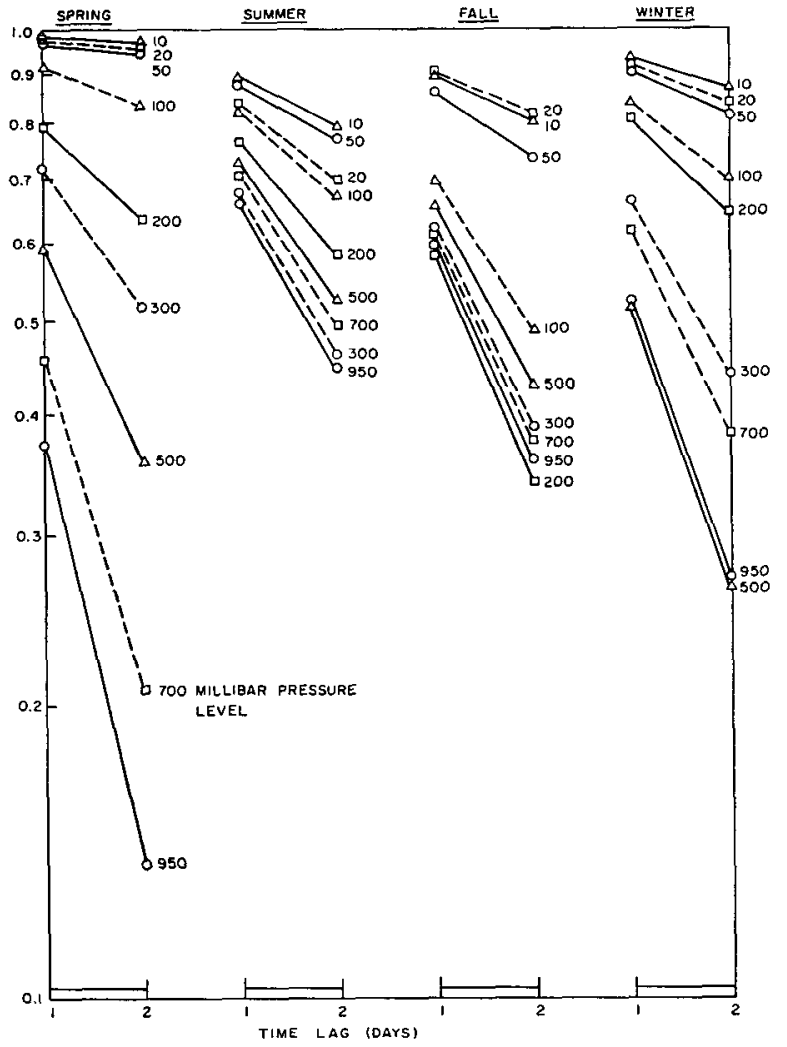

FIG. 9. Time-lag correlation coefficients, Nome, Alaska.

measurement errors were calculated as before. Resulting 24-hr regression forecast errors for Nome are shown in Figs. 10 and 11 which show: 1 ) errors from assuming a climatic average zonal wind; 2) errors from assuming persistence of the latest accurate observation; 3) errors from an ultimate BREEZE regression; and, finally, 4) errors from assuming persistence of erroneous observations. Results from similar analyses for Ely, Nev., and Albrook AFB, Canal Zone, are shown in Figs. 12 through 15 . The ultimate regression generally gives 2 to 9-kt improvements over persistence of erroneous observations. Percentage improvement varies depending on absolute values of variability which range from about $2 \mathrm{kt}$ to over $30 \mathrm{kt}$.

Lacking the detailed shorter-period lag correlations for stations other than Eniwetok causes larger correlation coefficient estimation errors and some questionable features to the verification patterns. In general, however, it is clearly shown that winds are quite steady in the stratosphere, particularly in summer. There is a large range of conditions which may eventually be encountered but these must be associated with long-wave developments. The apparent absence of short wavelength systems inferred by this analysis may also indicate lack of meso- and micro-scale turbulence. This was not assumed in derivation because the unexplained variance $m^{2}$ was stated to include small-scale turbulence 


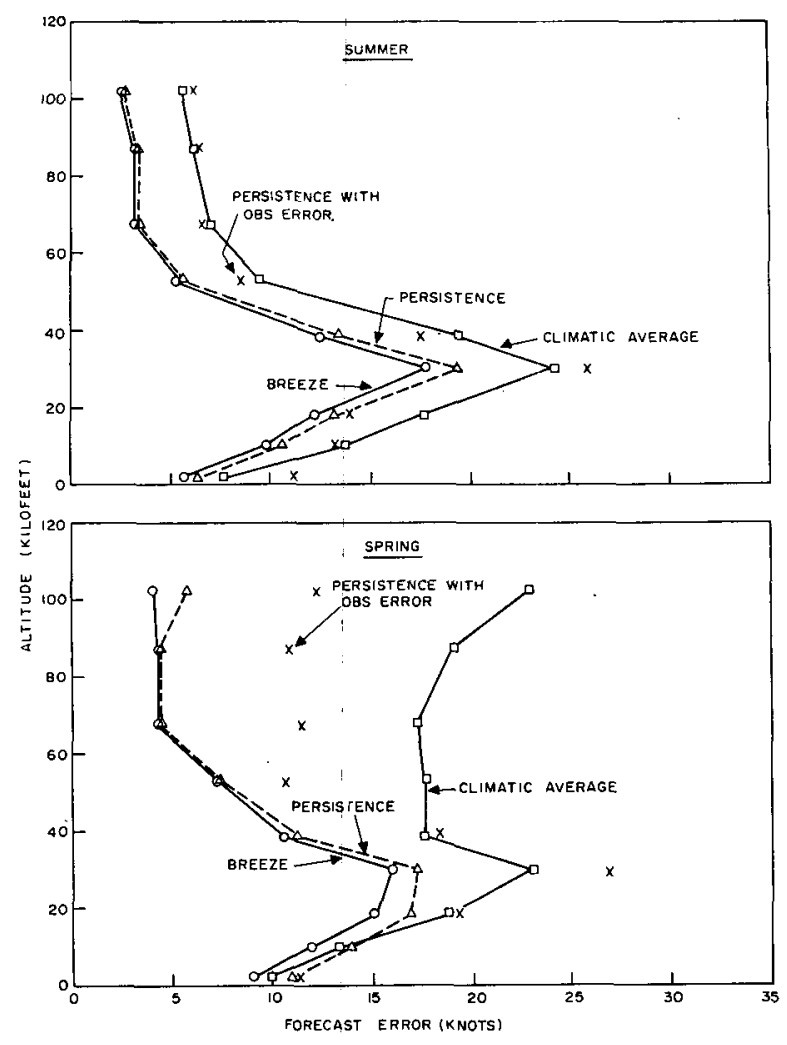

FIG. 10. Zonal wind 24-hr forecast errors, Nome, Alaska.

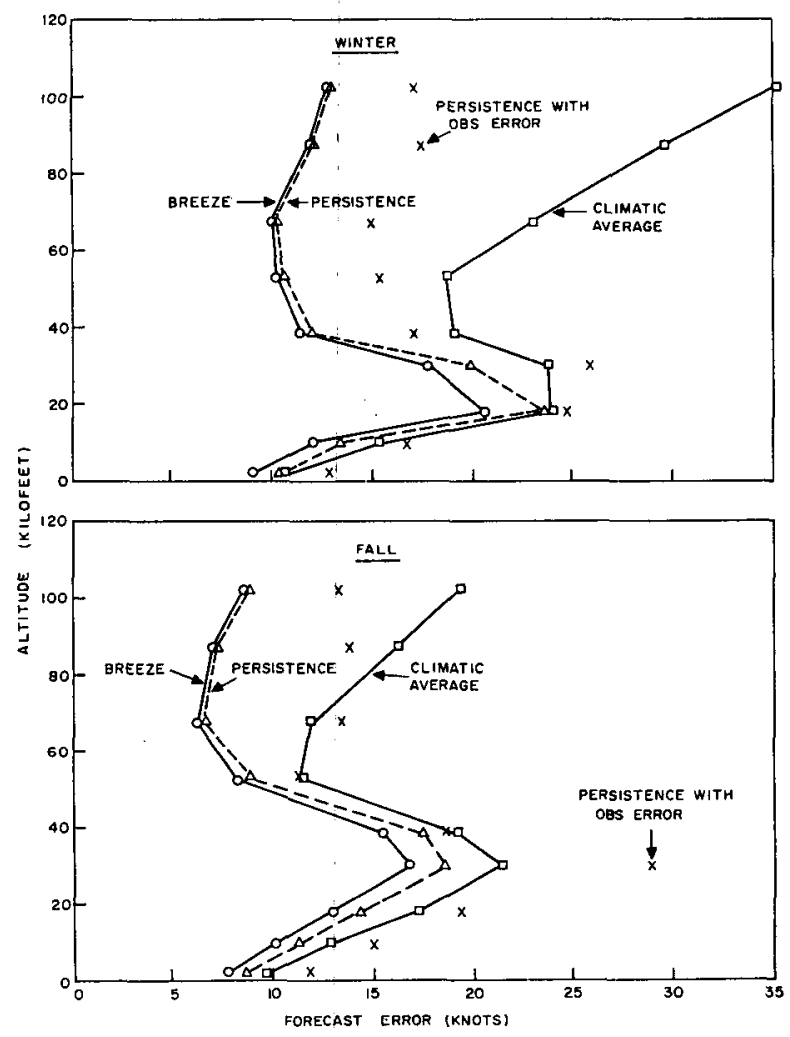

Fra. 11. Zonal wind 24thr forecast errors, Nome, Alaska.
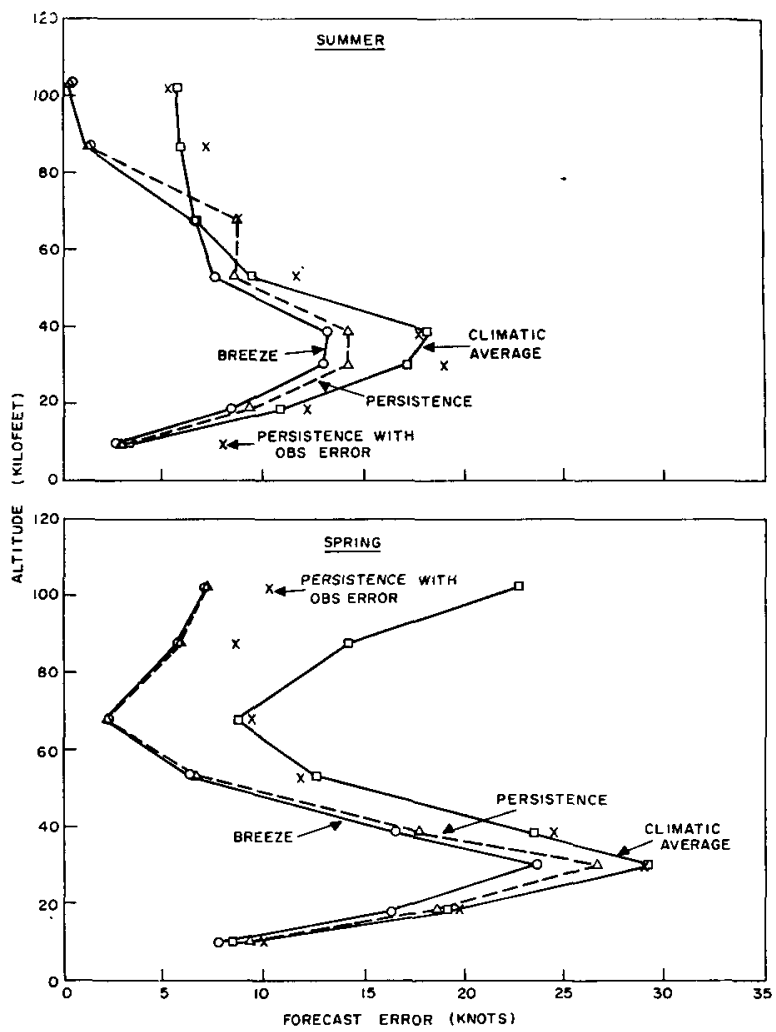

F'IG. 12. Zonal wind 24-hr forecast errors, Ely, Nev.

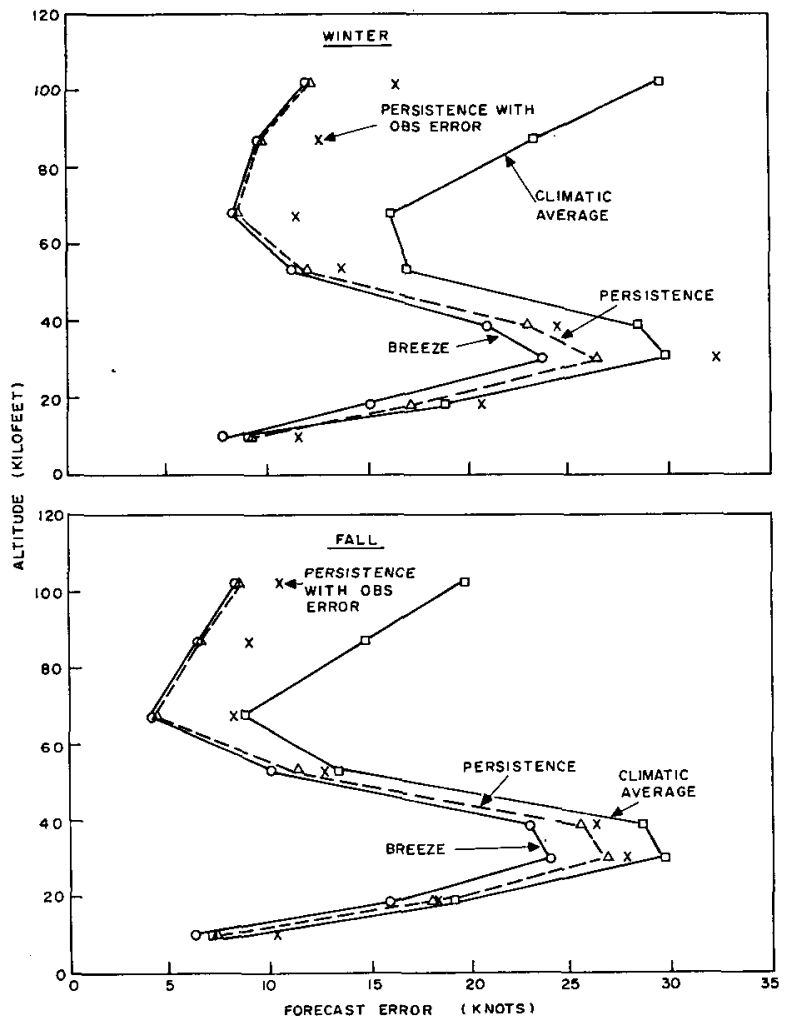

FIG. 13. Zonal wind 24-hr forecast erro:s, Ely, Nev. 
along with measurement error. An independent verification of the absence of high altitude turbulence would be valuable in planning for supersonic transport flight conditions. It would also improve understanding of downward transport of stratospheric fallout. It is planned to investigate this absence of turbulence in the near future, using artillery delivered smoke puffs which, if they are quite coherent and slow-moving, could be tracked by cameras for long periods of time in relatively light wind speeds.

\section{Applications}

A sample calculation from Eniwetok data was made for error potential versus forecast interval for regression forecasts. An rms correlation coefficient decay rate was computed from corrected data and the $e^{-1}$ decay times are plotted in Fig. 16. This shows the decay time constant is about 2 days at the surface, a little over 1 day at $10,000 \mathrm{ft}$, near 4 days at $30,000-50,000 \mathrm{ft}$, and about 3 months at $60,000 \mathrm{ft}$.

Forecast error curves are shown in Fig. 17. If an error limit is established from operational considerations, this curve shows the forecast interval which should not be exceeded. This graph also allows estimation of how much better forecasts would be obtained by waiting for "one more observation" before making an operation decision. It shows that at 40,000 ft 1-hr fore
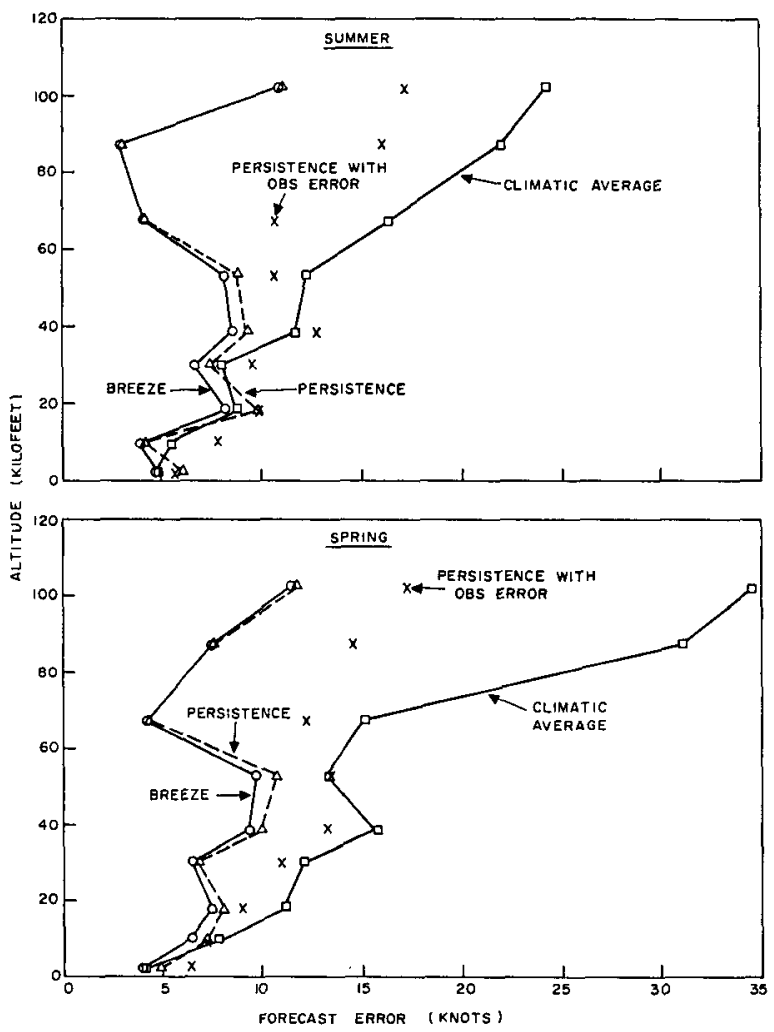

Fig. 14. Zonal wind 24-hr forecast errors, Albrook AFB, Canal Zone,
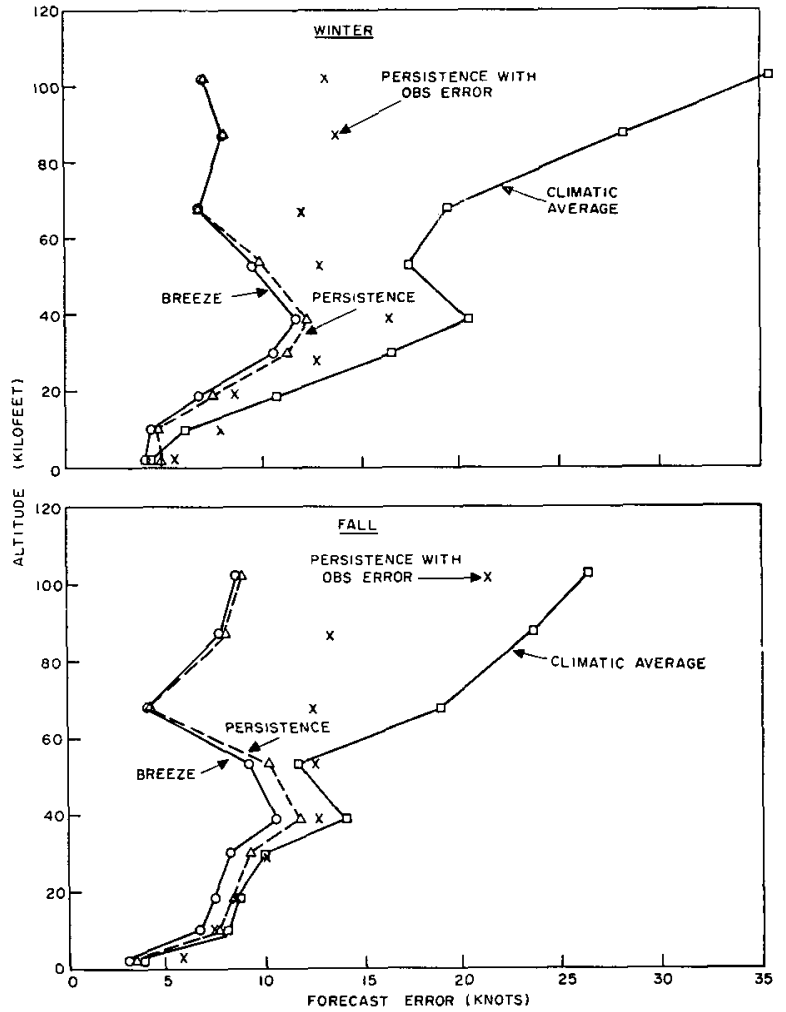

Fic. 15. Zonal wind 24-hr forecast errors, Albrook AFB, Canal Zone.

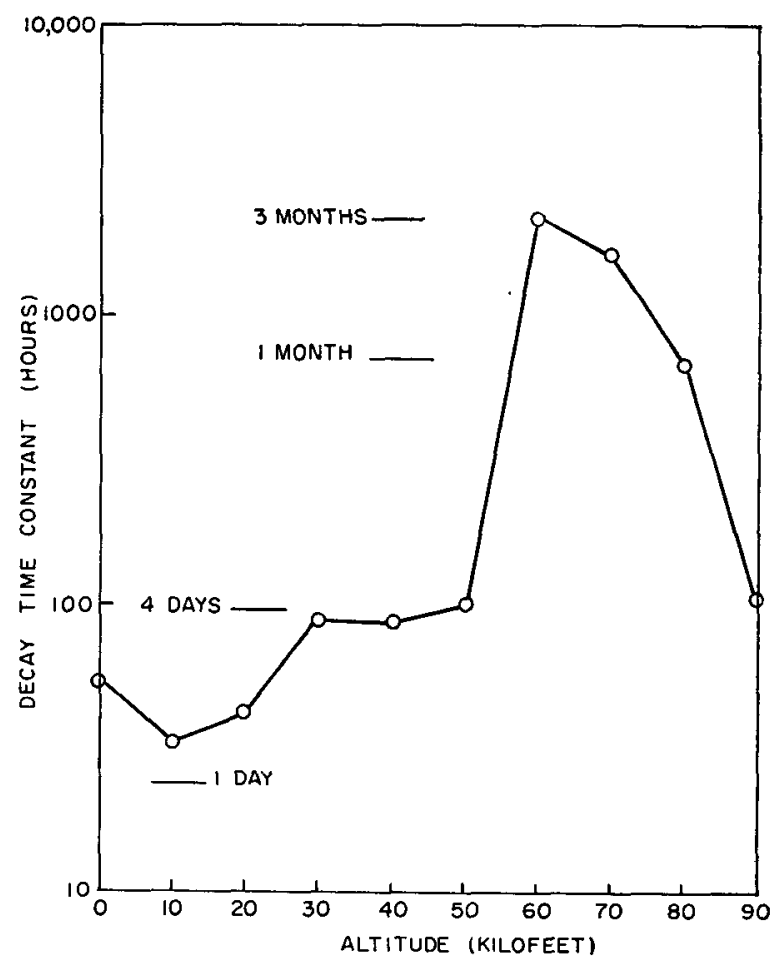

FIG. 16. Correlation decay time constants for 1956 Eniwetok data. 


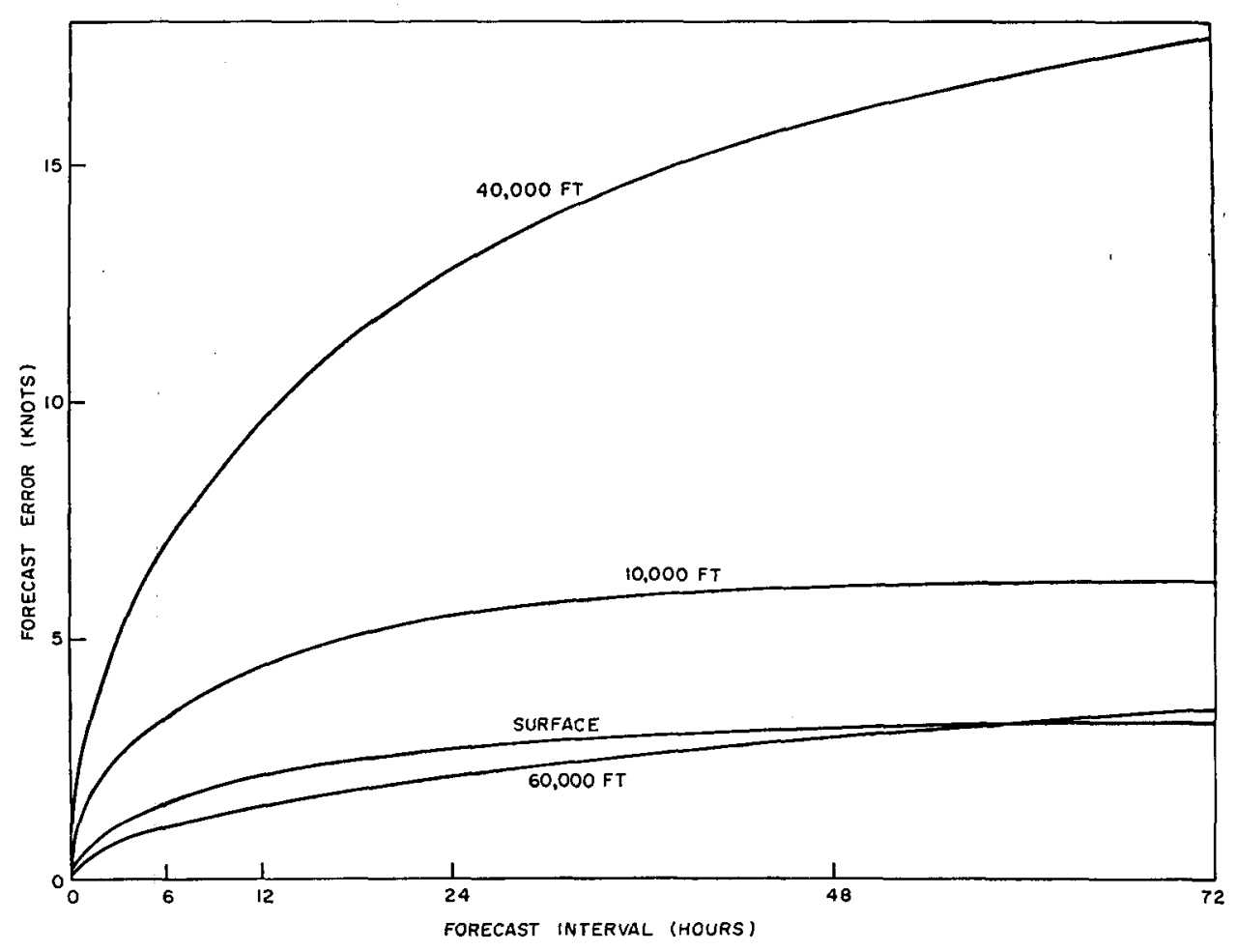

FIG. 17. Potential regression forecast accuracy for various altitudes vs. time (Eniwetok data).

casts have about the same error magnitude as 3-day forecasts for the surface or 60,000 -ft levels.

Results from these statistical studies may also be applied to the problem of predicting errors in forecast fallout patterns.

\section{Conclusions}

The most significant conclusion is that statistical regression wind forecasts can be considerably improved at several altitudes by removing effects of measurement errors and small scale turbulence. This can be accomplished simply by, at most, a combination of modern radar balloon tracking and multiple balloon observations which average out short-term turbulence effects.

Time-lag correlation coefficients, when corrected for measurement error, clearly decay exponentially with time and not time-squared. This leads to discounting history in regression forecasting, and concluding that the latest observation contains all the useful information.

A most amazing result is that after errors were removed there was practically no variability left in zonal winds at 60,000-80,000 ft. There may, in fact, be practically no turbulence or diffusivity in these regions.

Finally, the success of statistical regression forecasts in the tropics is probably not restricted to those lati- tudes. With less satisfactory data, however, it was found that regressions from accurate observations could have considerable forecast skill at all latitudes.

\section{REFERENCES}

Bannon, J. K., 1949: Angular deviation of the wind from the isobars at Liverpool. Quart. J. Roy. Meteor. Soc., 75, 131-146.

Bedient, H. A., and J. Vederman, 1964: Computer analysis and forecasting in the tropics. Mon. Wea. Rev., 92, 565-577.

Buell, C. E., 1958: Meaning of combined climate and persistence forecasts. $J$. Meteor., 15, 564-565.

Durst, C. S., 1954: The variation of wind with time and distance. Geophys. Memoirs, No. 93, Meteorological Office, Air Ministry, London.

Godson, W. L., 1950: A study of the deviations of wind speeds and directions from geostrophic values. Quart. J. Roy. Meteor. Soc., 76, 3-15.

Kays, M. D., 1966: A note on the comparison of rocket and estimated geostrophic winds at the 10-mb level. J. Appl. Meleor., 5, 129-131.

Kochanski, A., 1957: New methods of forecasting winds at 300 and $200 \mathrm{mb}$. Bull. Amer. Meteor. Soc., 38, 601-607.

Rapp, R. R., 1952: The effect of variability and instrumental error on measurements in the free atmosphere. Meteorological Papers, 2, No. 1, College of Engineering, New York University.

Reed, J. W., 1954: The representatives of winds-aloft observations. Bull. Amer. Meteor. Soc, 35, 253-256.

Weinstein, A. I., E. R. Reiter and J. R. Scoggins, 1966: Mesoscale structure of 11-20 km winds. J, Appl. Meteor., 5, 49-57. 